\title{
A COMPUTATIONAL APPROACH FOR EVALUATING HELICAL COMPRESSION SPRINGS
}

\author{
MacArthur L. Stewart ${ }^{1}$ \\ ${ }^{1}$ Assistant Professor, Mechanical Engineering Technology Department, Eastern Michigan University, MI, USA
}

\begin{abstract}
Helical compression springs are generally synthesized and evaluated by determining the maximum torsional stress, fatigue life, natural frequency, and/or load loss due to stress relaxation. To this end, researchers have developed finite element analysis (FEA) modeling methods to simulate the design performance of helical compression springs. The intent of this paper was to make a useful contribution to the published works for evaluating round wire helical compression springs. Specifically, commercially available FEA software was used to construct a structural model of a helical compression spring to simulate its full range of compression. The proposed FEA modeling methodology considers coil-to-coil contact and the end coils were modeled as rigid surfaces. With $9 \mathrm{~mm}$ of compression, the predicted spring rate correlated with the analytically calculated value to within $5 \%$.
\end{abstract}

Keywords: Helical compression spring, machine component design, spring FEA

\section{INTRODUCTION}

A helical compression spring is a common machine component that is used to exert a specific force at a specified height. Fig -1 shows the dimensional values that are used to define the geometry of a helical compression spring [1]. Note the diameter is defined as the mean of the inner and outer diameters, I.D. and O.D., respectively. The spring index $\mathrm{C}=\mathrm{D} / \mathrm{d}$ is a useful parameter for assessing manufacturability (ability to coil the spring) [1].

In general, helical compression spring design decisions are driven by the maximum torsional stress, fatigue life, natural frequency, and/or load loss due to stress relaxation (typical engineering design evaluation quantities). Because of this, efficient methods are needed to synthesize and evaluate potential spring design concepts.

There are 3 approaches for evaluating helical compression springs. 1) Experimental design evaluations has provided and continues to provide insight into the performance of potential spring design problem solutions. However, this approach may be difficult to execute in some cases. The area to be evaluated may not be accessible and/or the measuring equipment may interfere with the deflection of the spring. 2) For simple models, analytical equations may be considered. Analytical equations provide detailed knowledge of engineering quantities, i.e. stress distribution. 3) Besides experimental methods, complex spring models can be evaluated using numerical analysis methods. Particularly, finite deformation and boundary interaction effects can be estimated. But, the accuracy of a numerical model depends on the discretization strategy, material properties, and application of boundary conditions. Depending on the complexity of the model, solution times can also be long.

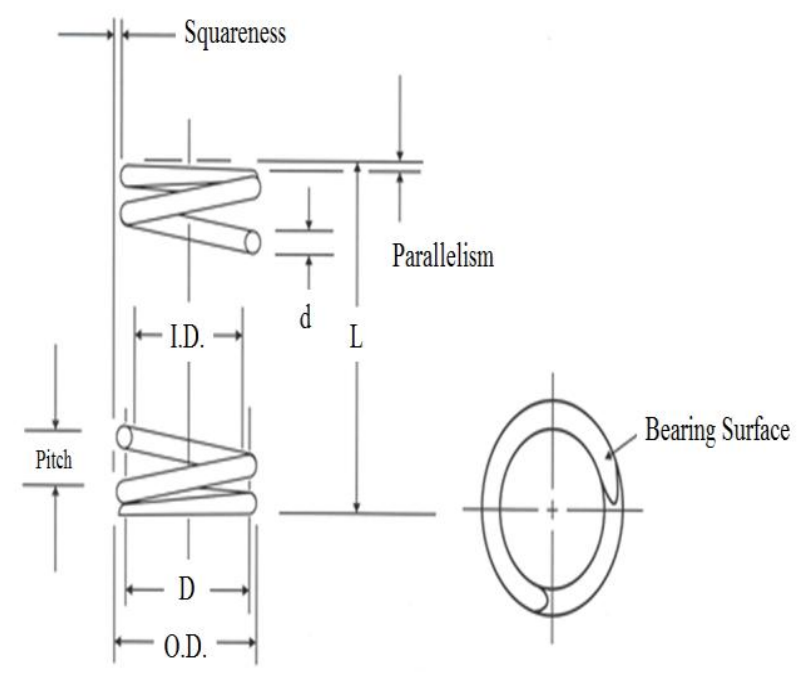

Fig -1: Dimensions of a helical compression spring

Researchers have proposed finite element analysis (FEA) modeling methods to predict the engineering design performance of helical compression springs. Investigators have developed linear FEA models to predict the maximum stress developed in helical compression springs used in the horn of two-wheel vehicles [2], [3]. Their FEA modeling methodologies correlated with analytical evaluations in the low load regime.

Scholars have also developed FEA models of helical compression springs applicable to vehicle suspension systems [4], [5]. The aim of these researchers was to replace steel with a viable composite material. Their results showed that the composite material resulted in a reduction in stress and weight, but an increase in displacement. Zhu et. al. [6] built a 2D FEA model to simulate contact between the end and first active coils using plane strain theory. The objective of their work was to determine the root cause of an 
automotive suspension spring fatigue failure. Along with experimental results, their FEA model indicated stress singularities at the edges of the contact zone which was concluded to be the cause of the fatigue failure.

In addition to discretizing helical compression spring geometry with tetrahedral and hexahedral elements, researchers have considered beam elements [7]. They used beam elements to increase computational efficiency.

The objective of this research was to make a useful contribution to the published works for synthesizing and evaluating helical compression springs. Specifically, this paper investigated the efficacy of modeling the end coils of a helical compression spring as rigid surfaces and using a contact algorithm to simulate coil-to-coil contact. The following assumptions were considered in this study:

- $\quad$ The spring was manufactured from steel, $\mathrm{E}=207$ GPa and $\square=0.3$

- The spring was free from material and manufacturing defects

- The loading frequency was not aligned with the spring's natural frequency

- The spring solid height could be calculated from the number of active coils $\mathrm{Na}$, wire diameter $\mathrm{d}$, and the spring end conditions

The major contributions to the published literature from this research include:

- A innovative methodology for constructing a virtual prototype of a helical compression spring

- A computationally efficient FEA modeling methodology that includes coil-to-coil contact

\section{HELICAL COMPRESSION SPRING}

\section{ANALYTICAL EQUATIONS}

Fig -2 shows a section of a round wire helical compression spring [8]. From these internal loads, analytical equations defining the shear stress at the inner coil of the spring $\square$ max and the spring rate $\mathrm{k}$ can be derived. A round wire helical compression spring can be thought of as a curved torsion bar. The shear stress is derived by considering the torsional stress that is developed in a straight bar and using the Wahl factor to account for the transverse shear force $\mathrm{F}$ and the effects of curvature [8]. So, the torsional shear stress in a bar subjected to a twisting moment $\mathrm{T}$ is

$$
\tau=\frac{\operatorname{Tr}}{\mathrm{J}},
$$

where $J$ is the polar moment of inertia $J\left(\frac{\pi}{32} D^{4}\right)$ and $r\left(\frac{d}{2}\right)$ is the radius of the cross sectional area. Substituting $\mathrm{J}$ and $\mathrm{r}$ into equation (1) gives

$$
\tau=\frac{16 \mathrm{~T}}{\pi \mathrm{d}^{3}}=\frac{8 \mathrm{FD}}{\pi \mathrm{d}^{3}} .
$$

The wall factor is defined by

$$
\left(\frac{4 \mathrm{C}-1}{4 \mathrm{C}-4}+\frac{0.615}{\mathrm{C}}\right)
$$

For static loading, the first term in equation (3) which accounts for the effects of curvature may be ignored [8].

The product of equations (2) and (3) gives the resultant shear stress that acts at the inner diameter of a round wire helical compression spring,

$$
\tau_{\max }=\frac{8 F D}{\pi d^{3}}\left(\frac{4 C-1}{4 C-4}+\frac{0.615}{C}\right) .
$$

By considering Castigliano's method and assuming that the transverse shear force $\mathrm{F}$ has a minimal effect on deflection, the spring rate is

$$
k=\frac{P}{F}=\frac{G d^{4}}{8 D^{3} N_{a}} .
$$

$\mathrm{G}$ and $\mathrm{Na}$ are the shear modulus of elasticity and the number of active coils, respectively.

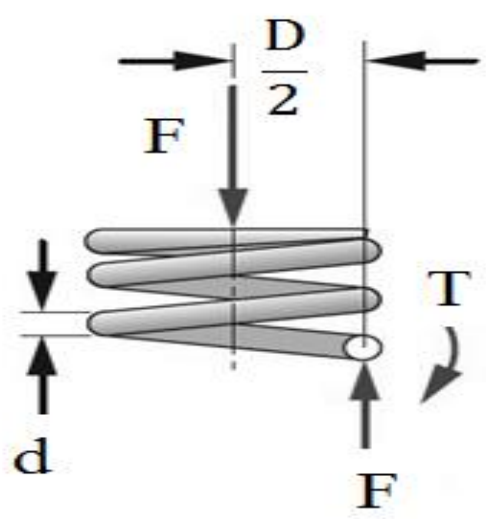

Fig -2: Section of round wire helical compression spring

\section{HELICAL COMPRESSION SPRING FEA MODEL}

In this work, two commercially available computer software programs were used as the primary research tools. 1) HyperMesh [9] was used to discretize the computational domain. HyperMesh is a FEA pre-processor, Altair Engineering, Inc. 2) Except for meshing, the FEA model was constructed and processed using MARC/Mentat which is a multi-purpose nonlinear FEA software package, MSC Software Corporation [10].

Fig -3 gives a general overview on how the proposed FEA model was constructed. This section contains a detailed description of the proposed FEA modeling methodology. Section 3 is organized into 5 subsections: 1) CAD data, 2) geometry discretization, 3) material properties, 4) boundary conditions, and 5) numerical solution methods. 


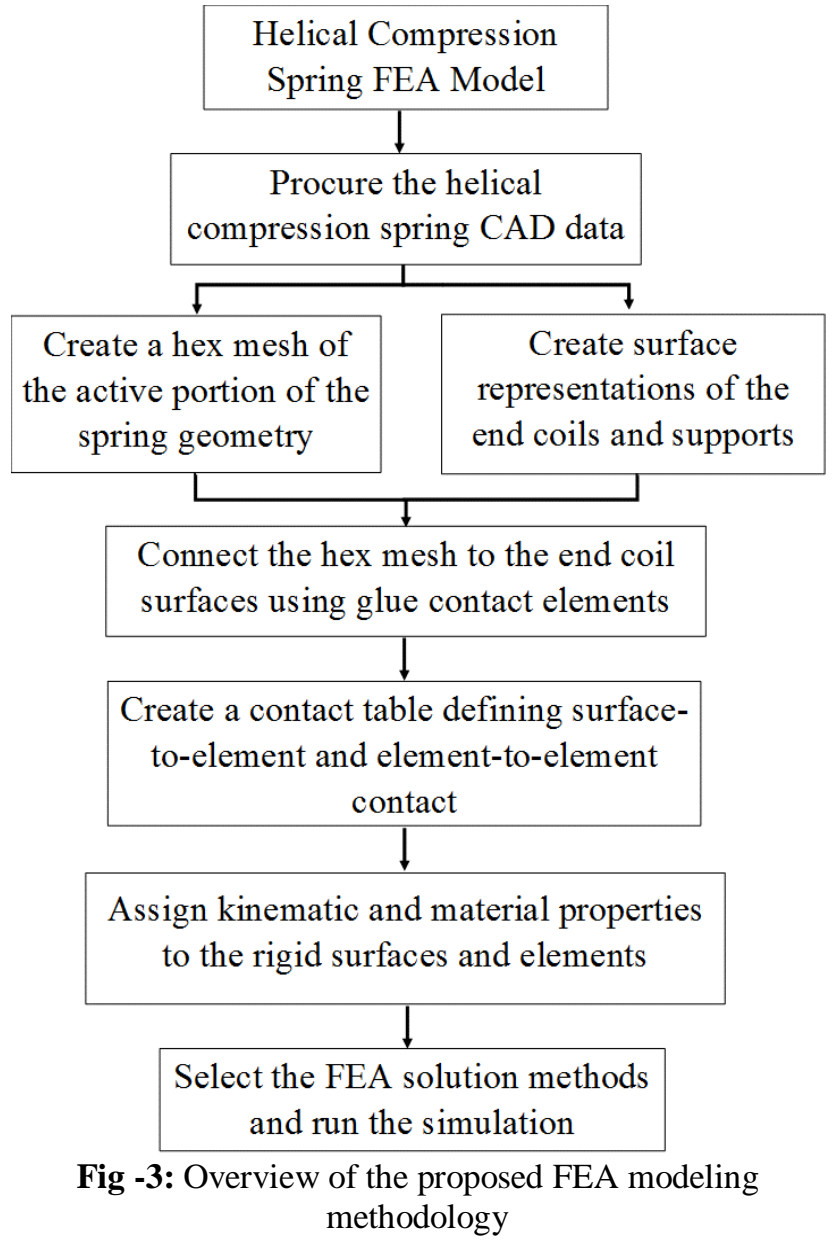

\subsection{CAD Data}

The proposed FEA modeling methodology was demonstrated on a helical compression spring with the following dimensions:

- $\quad$ Free length, $\mathrm{L}=30 \mathrm{~mm}$

- Wire diameter, $\mathrm{d}=3 \mathrm{~mm}$

- $\quad$ Outer diameter, $\mathrm{OD}=14 \mathrm{~mm}$

- $\quad$ Number of active coils, $\mathrm{Na}=7$

- Open and ground end coils

The CAD data is shown in Fig -4.

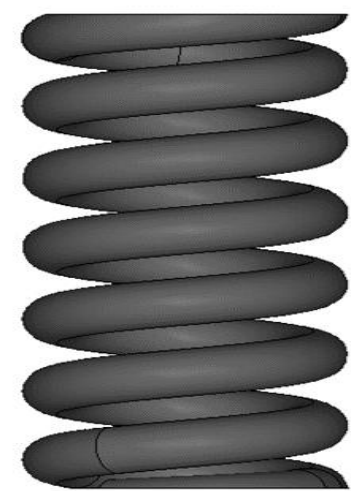

Fig -4: CAD data of the helical compression spring that was used in this study

\subsection{Geometry Discretization}

The CAD data that represented the geometry of the helical compression spring was first imported into HyperMesh. 11,296 linear hexahedral elements were used to discretize the active coil portion of the spring geometry, Fig -5 . Surfaces that represented the spring supports were integrated into the end coil surfaces. Glue type contact elements were used to create the interface between the end coil surfaces and the active coil solid mesh.

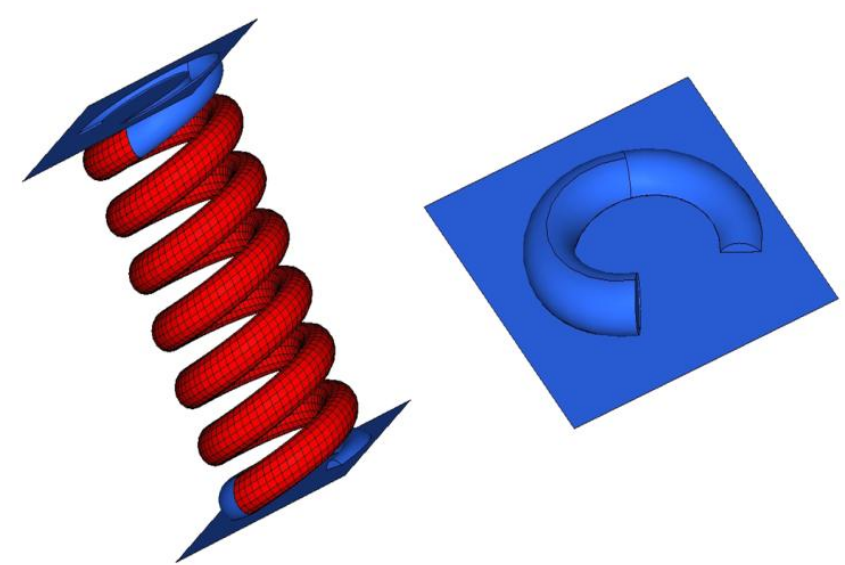

Fig -5: Helical compression spring FEA model: hexahedral FEA mesh representation of the active coils, glue contact elements were used to attach the end coil surfaces to the FE mesh (left); integrated end coil and spring support surfaces (right)

\subsection{Material Properties}

Similar to previous investigators [7], a linear constitutive relationship was assumed for this study. In other words, Hooke's Law was applicable. As previously stated, the spring was assumed to be fabricated from steel with the following properties: $\mathrm{E}=207 \mathrm{GPa}$, and $\square \square=0.3$. From the elastic modulus of elasticity $\mathrm{E}$ and assuming a value of 0.3 for poisson's ratio $\square$, the shear modulus of elasticity $G$ was calculated from

$$
G=\frac{E}{2(1+v)} .
$$

\subsection{Boundary Conditions}

The spring support surfaces were used to compress the spring FEA model from the free height to the solid height. To simulate coil contact during deformation, touching type contact elements were used to model boundary nonlinearity. Coulomb's friction model was used to account for coil friction. A value of 0.6 was considered for the coefficient of friction $\square$, steel on steel.

\subsection{Numerical Solution Methods}

The numerical methods that were used to simulate spring compression are summarized here:

- Element Type: $11,2961^{\text {st }}$ order hexahedral elements 
- Contact: touching contact, interface between the spring coils; glue contact, interface between the end coil surfaces and the active coil mesh

- Boundary Conditions: Rigid surfaces, displacement controlled

- Dynamic Effects: none (quasi static)

- Solution Control: Large displacement, Lagrangian, New-Raphson

- $\quad$ Stepping Procedure: Constant time step

- Convergence Criteria: Relative residual force magnitude, criteria $\leq 0.1$

\section{RESULTS}

After constructing the FEA model, spring compression was simulated by displacing the top integrated end coil/spring support surfaces. The bottom end coil/spring support surfaces remained stationary. In this section, the results of the simulation are presented. This section is organized into 2 subsections: 1) spring rate comparison, and 2) shear stress contour plots.

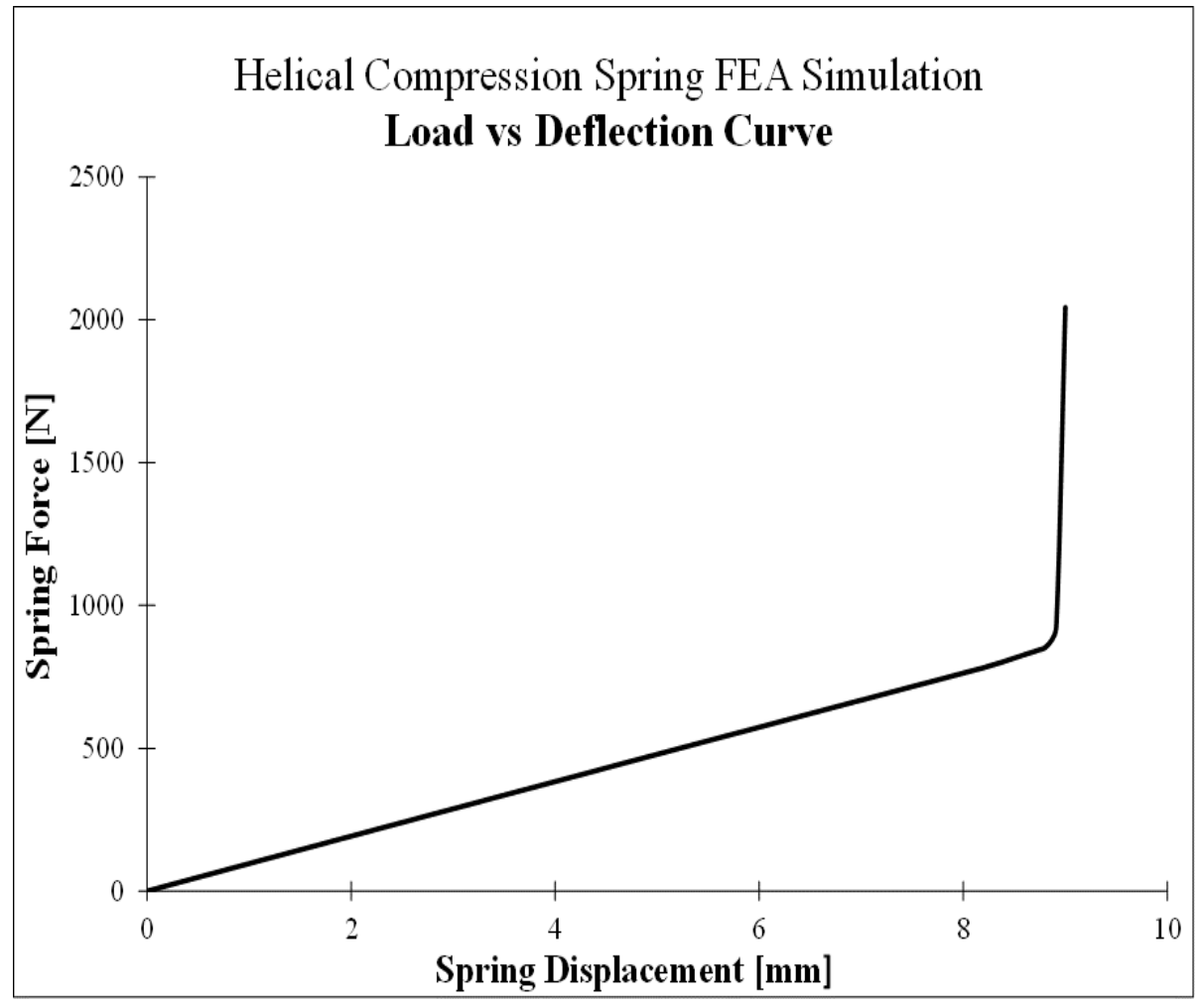

Fig -6: Predicted load vs deflection curve

\subsection{Spring Rate Comparison}

The spring rate curve was determined by calculating the reaction force (on the top spring support surface) at each displacement increment. Fig -6 shows the predicted spring load versus displacement curve. For the spring geometry used in this study, the available spring deflection is $9 \mathrm{~mm}$. Since the end coils of the spring were ground and flat, the expected deflection response would consist of a linear region within the deflection range of $10 \%-90 \%$ of the available spring deflection.

The spring rate in the linear region of Fig -6 is $95.4 \mathrm{~N} / \mathrm{mm}$. In comparison, the analytically calculated spring rate $\mathrm{k}$ was 91.3 $\mathrm{N} / \mathrm{mm}$. The relative error between the analytically calculated value and the FEA model prediction was $4.3 \%$. 


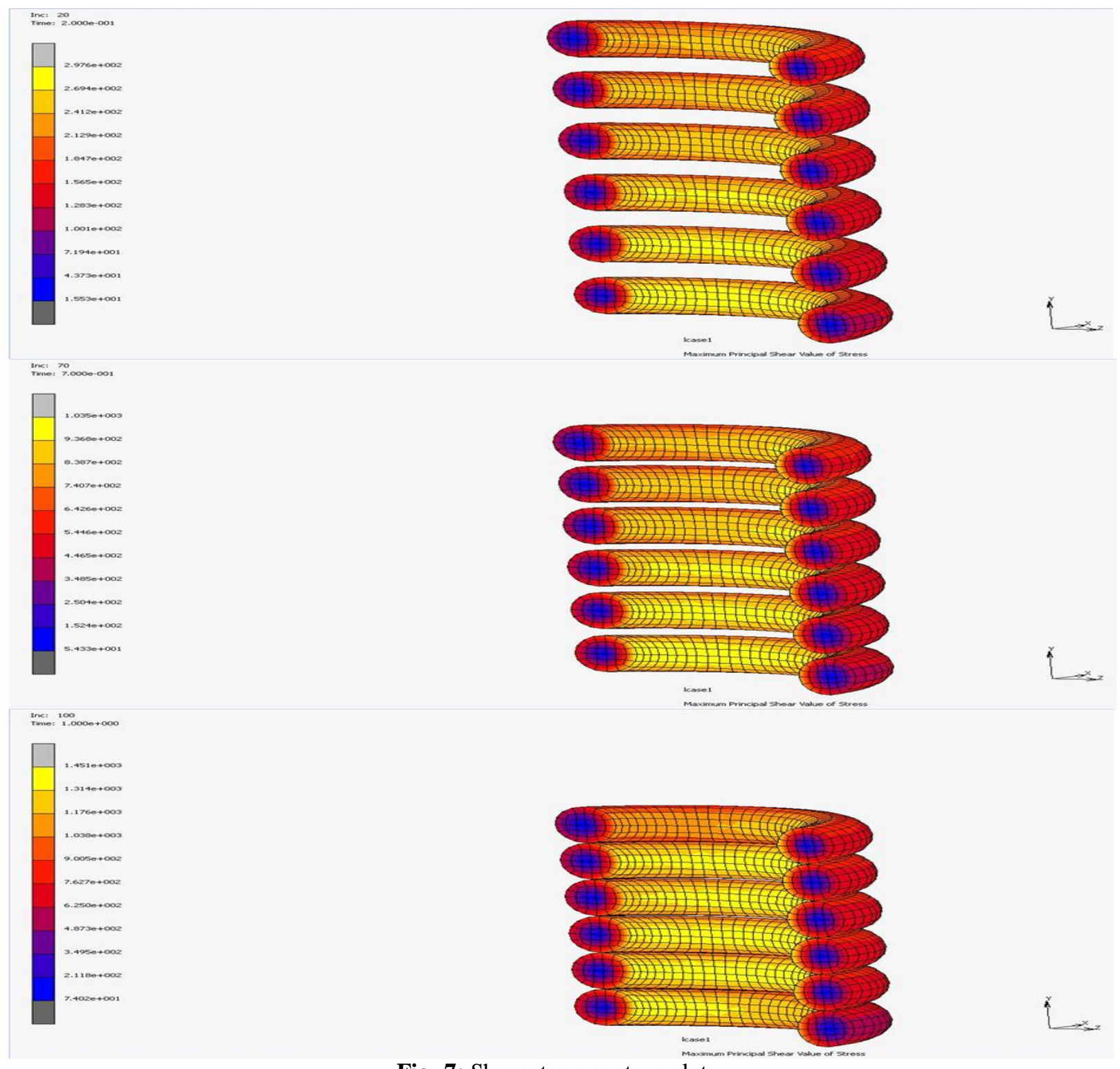

Fig -7: Shear stress contour plots

\subsection{Shear Stress Contour Plots}

Shear stress contour plots are shown in Fig -7. The contour plots at the top, middle, and bottom of Fig -7 represent the predicted shear stress at compression values of $1.8,6.3$, and $9 \mathrm{~mm}$ from the free height, respectively. Recall that the maximum spring deflection is $9 \mathrm{~mm}$.

The predicted maximum shear stress at $20 \%$ of the total deflection $(1.8 \mathrm{~mm})$ was $298 \mathrm{MPa}$ and the analytically computed value was $247 \mathrm{MPa}$. The resulting relative error was $17.1 \%$. At $70 \%$ of the available deflection $(6.3 \mathrm{~mm})$, the predicted maximum shear stress was $1035 \mathrm{MPa}$. The analytically computed value was $864.5 \mathrm{MPa}, 16.5 \%$ relative error. Note that the predicted maximum shear stress values were conservative.

Referring to the bottom contour plot in Fig -7, the predicted maximum shear stress when the spring was compressed to the solid height was $1451 \mathrm{MPa}$. Since the spring rate equation was derived assuming a linear relationship between the spring load and deflection and the fact that the degree of linearity is dependent on the conditions of the inactive coils, the accuracy of the predicted shear stress at the solid height should be based on an experimental evaluation. An experimental correlation study will be the topic of a future investigation.

\section{DISCUSSION}

Machine component design engineers could use the proposed CAE methodology to design and evaluate helical compression springs outside of the applicable range of analytical equations. For example, this method may be used to evaluate helical springs with complex geometries such as variable rate springs. In addition, it can be used to design helical compression springs to operate up to their solid height. This would optimize the use of material, thus reducing material cost and weight. Besides design evaluations, the proposed methodology may be used to support spring failure analysis. 


\section{CONCLUSION}

In conclusion, this research made two points. 1) A computationally efficient and accurate FEA model of a helical compression spring can be constructed that includes end coil effects and coil-to-coil contact. The FE mesh contained 11,296 hexahedral elements. The predicted spring rate was within $5 \%$ of the analytically calculated value. 2 ) The end coils can be modeled as rigid surfaces. Glue type contact elements was an enabler for attaching rigid surface representations of the end coils to the FE mesh representation of the active coils. In future work, experimental methods will be used to study the efficacy of the proposed FEA modeling methodology for predicting nonlinear engineering quantities, i.e. plastic deformation, stress relaxation, and impact loads.

\section{REFERENCES}

[1]. Associated Spring, "Design Handbook: An Engineering Guide to Spring Design." 1987.

[2]. S.S. Gaikwad, P.S. Kachare. "Static Analysis of Helical Compression Spring Used in Two-Wheeler Horn.”IJET, pp. 161-165, Feb 2013.

[3]. P. Sangmesh, S.J. Sanjay, V.B. Math. "Static Analysis of Helical Compression Spring." IJRET, pp. 835-838, May 2014.

[4]. M. Bakhshesh, M. Bakhshesh. "Optimization of Steel elical Spring by Composite Spring." IJMSE, pp. 47-41, June 2012.

[5]. S.S. Bhatia, A. Bergaley. "Analysis of the Design of Helical Compression Spring to Study the Behavior of Steel and Composites Used as a Spring Material." IJESRT, pp. 576- 583, Aug 2014.

[6]. Y. Zhu, Y. Wang, Y. Huang. "Failure Analysis of a Helical Compression Spring for a Heavy Vehicle Suspension System." Case Studies in Engineering Failure Analysis, pp. 169-173, Oct 2014.

[7]. S. Valsange. "Design of Helical Coil Compression Spring, a Review." IJERA, pp 513-522, Nov 2012.

[8]. R.C. Juvinall, K.M. Marshek. "Fundamentals of Machine Component Design." New York: John Wiley and Sons; 1991.

[9]. Altair Engineering, "HyperMesh 12, User Manual." 2012.

[10]. MSC Software Corporation, "Volume A: theory and user Manual." 2013. 